\title{
Simultaneous Use of 3 D Locking Square Plate and 2 Mm Straight Miniplate for Mandibular Fracture: A Case Report and Review of Literature
}

\author{
Akshay Kumar ${ }^{1}$ Dhrittiman Pathak ${ }^{2}$, Amit Kumar Verma ${ }^{3}$, Pramod Yadav \\ 1 Oral and Maxillofacial Surgeon, CH BSF Srinagar, India. \\ ${ }^{2}$ Consultant Maxillofacial Surgeon, Sarvodaya Healthcare, Guwahati, Visiting Consultant, Apollo \\ Hospital, Guwahati, India. \\ 3Prosthodontics and Oral Implantologist, ESIC Hospital, Behrampur, Bengal, India. \\ ${ }^{4}$ Department of Periodontics and Community Dentistry, Dr. Z. A. Dental College AMU Aligarh, India.
}

\section{ABSTRACT}

Champy plates are becoming more and more accepted for the fixation of simple mandibular fractures. Champy plates have the following advantages over other metbods: the plates are small, flexible, easily adaptable and the monocortical screws allow a rapid surgical application. This case report and literature review examined the use of a locking bone plate/screw system for use in mandibular surgery. The use of a locking plate/screw system was found to be simple, and it offers advantages over conventional bone plates by not requiring the plate to be compressed to the bone to provide stability.

Keywords: Champy, 3D, Fracture, Locking, Mandibular Fracture, Miniplate, Simultaneous.

Address for Correspondence Author

Dr. Pramod Kumar Yadav; Department of Periodontics and Community Dentistry, Dr. Z. A. Dental College, AMU, Aligarh, Uttar Pradesh, India.

E-mail: pramod468@gmail.com

Crossref Doi: https://doi.org/10.36437/irmhs.2020.3.1.E

\section{Introduction}

With the development of osteosynthesis in maxillofacial surgery different systems have been designed which have become smaller, more simple to handle and avoid extra oral procedures. Meanwhile, Miniplate fixation of mandibular fractures has become a standard treatment. Nevertheless, complications in Miniplate osteosynthesis of the mandible especially in the angular region have been described in up to thirty percent of cases, like movement and loosening of screws following the failure of fracture treatment. Also, plate pressure following disturbance of the blood supply and bone necrosis especially around the screws will lead to loss of plate friction. In order to improve Miniplate osteosynthesis, a new internal Mini-Locking-System has been developed in collaboration with the AO/ASIF-Institute (Davos, Switzerland) ${ }^{1}$.

Osteosynthesis with miniaturized screwed plates in maxillofacial surgery was first advocated by MICHELET in 1973. This method made it possible to immobilize the fractured mandible by an intraoral route. Thereafter, CHAMPY demonstrated that monocortica1, juxta alveolar, 
and subapical osteosynthesis, without compression and intermaxillary fixation, could be used in many types of mandibular fractures. Since the introduction of the Champy miniplate in the treatment of mandibular fractures, the potential and effectiveness of this method have been demonstrated in many clinical studies².

In spite of the encouraging results, some authors have raised doubts as to the functional stability of miniplates, especially for angle fractures. Biomechanical studies have found distraction of the lower border of the mandible when vertical loading forces are applied close to the fracture line. Some authors, therefore, recommend the use of two miniplates one placed at the superior and a second one at the inferior border of the angle region ${ }^{3}$.

Currently, two different types of miniplate systems are available: 3-dimensional miniplates and standard miniplates. The ideal method of treatment of mandibular fractures should aim for perfect anatomic reduction, stable fixation, and painless mobilization of the injured region around its articulation. The use of 3-dimensional (3D) strut plates is one of the methods of fixation that has emerged as a challenge to the Champy technique for the fixation of mandibular fractures and has been the topic of a growing number of clinical studies ${ }^{4}$.

The 3D plates can be considered as a two-plate system, with two miniplates joined by interconnecting crossbars. Their shape is based on the principle of a quadrilateral is a geometrically stable configuration for support. Because the screws are arranged in the configuration of a box on both sides of the fracture, a broadband platform is created, increasing the resistance to twisting and bending the long axis of the plate. There is a simultaneous stabilization of the tension and compression over that of conventional miniplates. Moreover, this system is simple to apply because of its malleability, low profile (reduced palpability), and ease of application (requiring little or no additional contouring) 5 .

\section{A Case Report}

A 31-year-old male patient reported to Composite hospital, BSF, Srinagar with a chief complaint of pain and reduced mouth opening for 2 days. A patient gives a history of road traffic injury while riding a motorcycle. No history of loss of consciousness, nasal and ear bleed was present. On intraoral clinical examination, occlusion is deranged, step deformity present between 43, 44, 33, 34 and extraorally multiple abrasions are present on the face with step deformity at right and left parasymphysis region. Routine blood investigation was done; OPG and CT scan of a face with 3D reconstruction were adviced. Based on radiographic and CT evaluation final diagnosis of bilateral parasymphysis of mandible fracture was made. ORIF under GA was planned using $2 \mathrm{~mm}$ miniplate and $3 \mathrm{D}$ locking square plates. After getting written consent, the patient was taken up for GA. Nasal intubation was done, after proper painting and drapping arch bar was tied to both maxillary and mandibular arches, intraorally both fracture sites were exposed using degloving incision. Occlusion was achieved prior to fixation of two $2 \mathrm{~mm}$ miniplate using $6 \mathrm{~mm}$ and $8 \mathrm{~mm}$ screws and $3 \mathrm{D}$ locking square plate using $6 \mathrm{~mm}$ locking screws at the left and right parasymphysis region. Layer wise closure was done. Postoperatively antibiotics and analgesics are prescribed and the patient was kept on IMF for 21 days. Our purpose is to present a case report and review the history of locking plates and the current recommendations for the use of those devices and to look toward future trends in the clinical application of locking plates. 


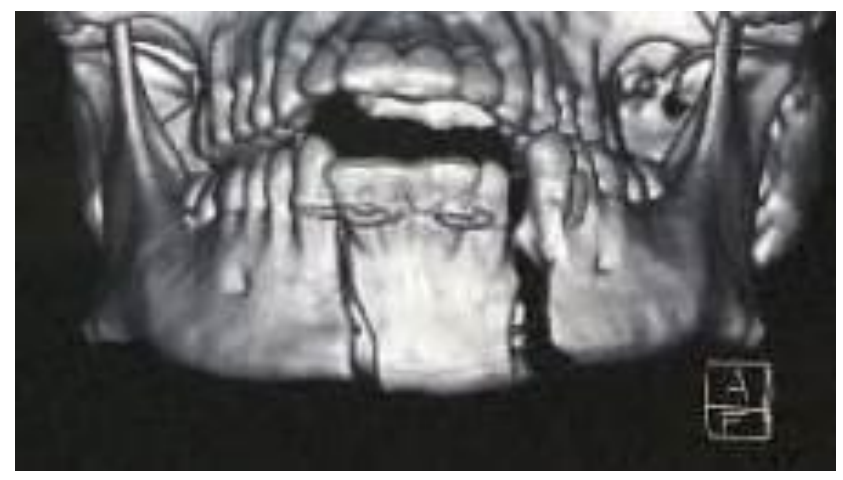

Figure 1: Pre 0p CT Scan

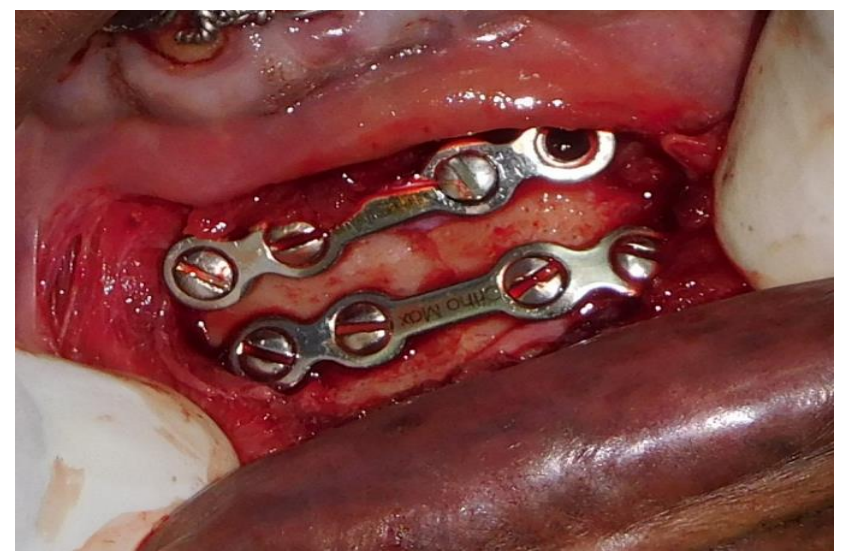

Figure 2: 2mm Miniplate Fixation

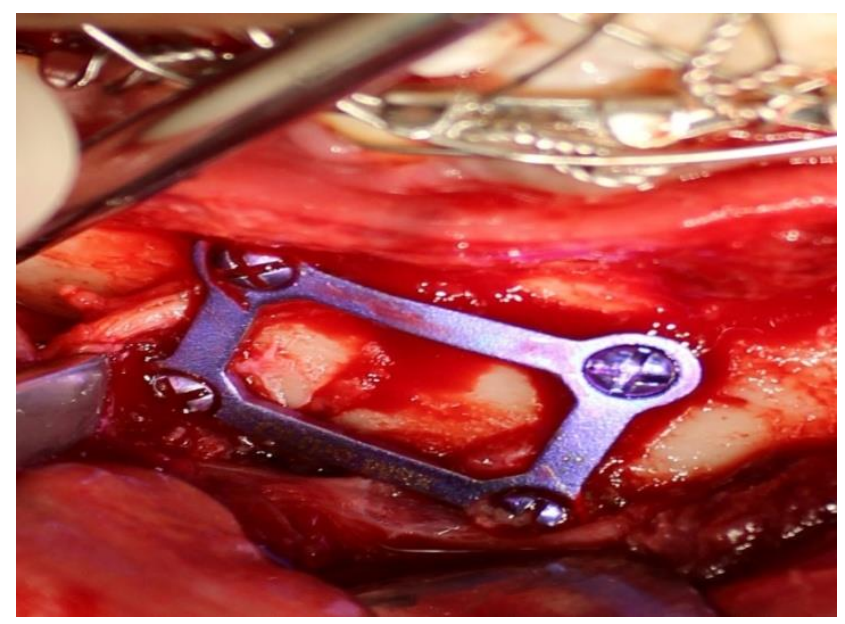

Figure 3: 3D Locking Plate Fixation

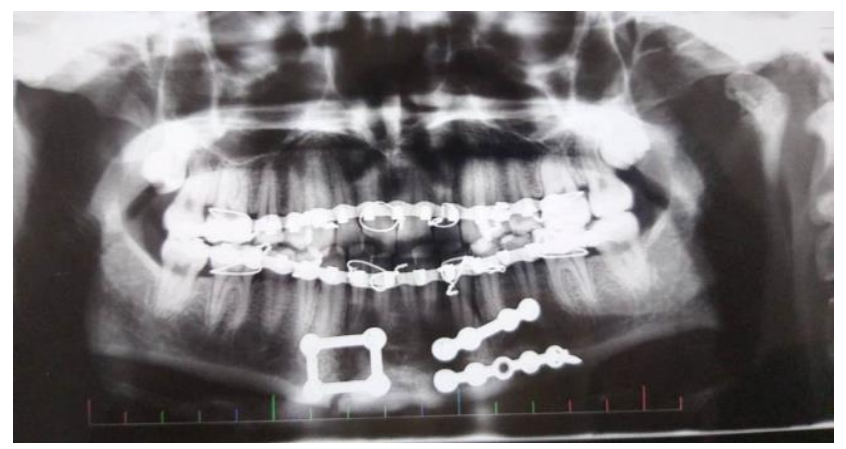

Figure 4: Post op OPG

\section{Discussion}

Mandibular fractures are common. A variety of different treatment methods for MFs have been described. The key to successful management of these fractures is to understand the principles of the accurate re-establishment of occlusion, fracture reduction, and stable internal fixation. 6 The purpose of this review is to verify and evaluate the following: What is the best fixation method with the fewest postoperative complications? Is there a significant difference in the clinical outcomes between standard and 3dimensional miniplate fixation in the treatment of Mandibular fractures? In general, the results of the review show mandibular fractures treated with 3 D locking miniplates present less shortterm complication rates. The low postoperative maxillomandibular fixation rate of using $3 \mathrm{D}$ locking miniplates also indicates that it has a promising application in the treatment of mandibular fractures.

Kroon et al. (1991)7 reported that the Champy miniplate fixation technique provides excellent results in terms of open and close movements of the jaw but cannot reliably stabilize the fixation during lateral movements of the mandible. Levy et al. (1991) ${ }^{8}$ observed a significantly higher rate of complications in patients with mandibular angle fractures who were treated with one miniplate compared to patients whose fractures were fixed 
with two miniplates. Several studies conclude that the placement of a second miniplate in the caudal region of the mandibular angle results in higher stability and is a reliable and effective technique (Choi et al.9, 1995; Fox and Kellman10, 2003). In 2013, Chrcanovic11 found that the use of two miniplates provides greater biomechanical stability and prevents lateral displacement or even opening of the inferior fracture gap.

Miniplate osteosynthesis can be optimized only if the advantages of available techniques are combined. For example, fracture treatment with a single plate is associated with less tissue trauma and shorter operating times, whereas two plates improve torsional stiffness. When a locking screw is inserted through a locking plate, a tight and permanent connection is created on the basis of the principle of cold welding. The locking system offers the benefits of multidirectional screw placement, which means that screws can be inserted at different angles and thus facilitate in particular the management of complex fractures (Wolter12, 1999). Several clinical studies have shown that mandibular fractures treated with locking miniplates and standard plates present similar short-term complication rates; however, locking miniplates offer significant advantages over conventional plating systems since they provide higher stability and do not require precise adaptation (Collins et al 13, 2004; Singh et al14, 2011; Kumar et al15, 2015).

According to a study conducted by Dhananjay $\mathrm{H}$ Barde et al $^{\mathbf{1 6}}$ for comparing the efficacy of $3 \mathrm{D}$ plates over Champy's miniplates in mandibular anterior fractures, it was concluded that the fixation of fractures in the anterior region of the mandible with 3D plates provided better threedimensional stability probably due to the geometric configuration and had lesser rates of infection and morbidity postoperatively. They also made a note that probably the most common limitation was the use of excessive implant material, but concluded that they are comparatively better alternative to Champy's miniplates. In this present study, another disadvantage that was observed was the increased cost that had to be borne by the patient, but the surgeon was well aware of this extra cost that was borne by the patient and it was also taken into consideration while choosing the sample for this study. The other disadvantage was the broad size of the 3D titanium plate which makes it difficult to use in atrophic mandible, as manipulation and fixation of these plates could have possibly resulted in pathological fractures ${ }^{17}$.

In another study conducted by Bipin S. Sadhwani et al18 in 2014, comparing conventional $2.0 \mathrm{~mm}$ miniplates and 3D plates for the management of mandibular fractures, they found that the 3D plates had lower postoperative complications in terms of morbidity and infection, In 2011, Mohit Agarwal et al ${ }^{19}$ conducted a study comparing the efficacy of 2-mm locking miniplates and 2-mm standard miniplates in the management of mandibular fractures based on improvement in various clinical parameters and bite force measurement. They concluded that the use of locking miniplates for the purpose of fixation in the management of mandibular fractures was comparatively more efficacious in terms of better plate adaptation, stability, minimal compromise of the periosteal blood supply, along with the advantage of increased postoperative bite force measurements. There is not much difference in the armamentarium for the locking system as it requires only a few minor additions.

Computerized tomography (CT) has been found superior to plain radiography as it improves understanding of the nature of mandibular fractures. It provides more information regarding 
fracture displacement and comminution and may visualize injuries that are otherwise missed ${ }^{20}$. CT has been used for measuring bone density to determine the quality of bone at implant site21, quality of newly formed bone after alveolar distraction ${ }^{22}$, bone healing after $\mathrm{BSSO}^{23}$, and bone healing after fracture fixation, Many studies measured inter-ramus distance on 3D CT to assess the stability of the proximal bony segments after bilateral sagittal split osteotomy (BSSO).

E. A. Al-Moraissi24 et al showed the 3D miniplate to have complication rates comparable to those of standard miniplates. A systematic review and meta-analysis of six studies $25,26,27,28,29,30$ comparing 3D geometric plates to miniplates placed according to Champy's principles were recently published. It was concluded that there is a lower complication rate with the use of 3D miniplate fixation in comparison with the use of standard miniplate fixation in the management of mandibular fractures. This could be attributed in part to the small sample size of the present study and also to the fact that previous studies have not included hardware palpability as a complication.

The advantage of the 3D plates is that they provide improved mechanical stability as compared to the conventional mini-plates, although that additional stability may be lost in the case of oblique fractures. The reason for this is that in oblique fractures it is difficult to reconcile all the recommendations for an ideal fixation using a device that consists of horizontal bars and vertical bars parallel to the fracture line. This may explain the differences in resistance encountered among the fixation devices in this study according to the type of fracture. The principles and utilization of 3D miniplates in mandibular fractures have not yet been fully established. In a recent research survey among 104 American and European dental surgeons belonging to the
Association for Osteosynthesis/Association for the Study of Internal Fixation (AO/ASIF), only 6\% declared that they made use of such materials for fixation.33 Furthermore, there are no case series reports available in the specialized literature and only a small number of published studies investigating their advantages as compared to traditional plates and mini-plates for bone reconstruction 31 .

A variety of different treatment modalities for the treatment of MAFs have been described. The Champy technique has probably been the most commonly used method of fixation to date. Champy et al. recommended a single noncompression miniplate, ventral to the oblique line, for mandibular fractures. Although this technique has been documented to have low complication rates in some studies, as observed in a recent review, the stability of single miniplate fixation for mandibular fractures has been challenged in several biomechanical studies. The use of one standard miniplate leads to the opening of the fracture line at the lower border, lateral displacement of the fragments at the inferior border, and posterior open bite on the fracture side, and this fracture movement is thought to contribute to subsequent complications. More recently, 3D titanium miniplates and screws have been developed. One of the advantages of the technique is the simultaneous stabilization of the tension and compression zones, making the 3D plates a time-saving alternative to conventional miniplates. Although the strut plate is relatively new in the management of mandibular fractures, it has demonstrated good clinical results in the literature ${ }^{32}$.

\section{Conclusion}

The results of this review identified lower complication rates with the use of 3D miniplate fixation in comparison with the use of standard 
miniplate fixation in the management of mandibular fractures. It is suggested that the advantages of this technique are not limited to technical ease (as presented in the literature), but also include lower patient morbidity.

\section{References}

1. Gutwald R, Alpert B, Schmelzeisen R. Principle and stability of locking plates. Keio J Med 200352 (1): 21-24.

2. Ikemura K, Kouno Y, Shibata H, Yamasaki K. Biomechanical study on monocortical osteosynthesis for the fracture of the mandible. Int. J. Oral Surg. 1984: 13: 307312.

3. Gerlach KL, Schwarz A. Bite forces in patients after treatment of mandibular angle fractures with miniplate osteosynthesis according to Champy. Int. J. Oral Maxillofac. Surg. 2002; 31: 345-348.

4. Kubiak EN, Fulkerson E, Strauss E, Kenneth A. Egol. The Evolution of Locked Plates. J. Bone Joint Surg. Am. 2006 88:189-200.

5. Silajiding $K$, Wusiman $P$, Yusufu $B$, Moming A. Three dimentional versus standard miniplate fixation in the management of mandibulaar fractures: A meta analysis of randomized controlled trials. Kaohsiung Journal of Medical Sciences 2017 33, 464-472.

6. Zimmermann $\mathrm{C}$ et al. Biomechanical comparison of a multidirectional locking plate and conventional plates for the osteosynthesis of mandibular angle fractures- A preliminary study. Journal of Cranio-Maxillo-Facial Surgery 452017 1913-1920.

7. Kroon FH, Mathisson M, Cordey JR, Rahn BA: The use of miniplates in mandibular fractures. An in vitro study. J Craniomaxillofac Surg 19: 199e204, 1991.
8. Levy FE, Smith RW, Odland RM, Marentette LJ: Monocortical miniplate fixation of mandibular angle fractures. Arch Otolaryngol Head Neck Surg 117: 149e154, 1991.

9. Choi B, Kim K, Kang H: Clinical and in vitro evaluation of mandibular angle fracture fixation with two-miniplate system. J Oral Surg 79: 692e695, 1995.

10. Fox AJ, Kellman RM: Mandibular angle fractures: two-miniplate fixation and complications. Arch Facial Plast Surg 5: 464e469, 2003.

11. Chrcanovic BR: Fixation of mandibular angle fractures: in vitro biomechanical assessments and computer-based studies. Oral Maxillofac Surg 17: 251e268, 2013.

12. Wolter D: Fixateur-interne-Systeme. Trauma Berufskrankh 1: 307e319, 1999

13. Collins CP, Pirinjian-Leonard G, Tolas A, Alcalde R: A prospective randomized clinical trial comparing 2.0-mm locking plates to $2.0-\mathrm{mm}$ standard plates in treatment of mandible fractures. J Oral Maxillofac Surg 62: 1392e1395, 2004

14. Singh V, Kumar I, Bhagol A: Comparative evaluation of $2.0-\mathrm{mm}$ locking plate system vs $2.0-\mathrm{mm}$ nonlocking plate system for mandibular fracture: a prospective randomized study. Int J Oral Maxillofac Surg 40: 372e377, 2011

15. Kumar BP, Kumar KA, Venkatesh V, Mohan AP, Ramesh K, Mallikarjun K: Study of efficacy and the comparison between $2.0 \mathrm{~mm}$ locking plating system and $2.0 \mathrm{~mm}$ standard plating system in mandibular fractures. J Maxillofac Oral Surg 14: 799e807, 2015

16. Dhananjay H Barde, AnupamaMudhol, FareediMukram Ali, Madan RS, Sanjay Kar, FarheenUstaad .Efficacy of 3-dimensional plates over Champys miniplates in 
mandibular anterior fractures.J Int Oral Health .2014;6(1):20-26

17. George D et al. A Comparative Study Between Titanium Mini Plates And 3 Dimensional Titanium Plates With Locking Screws Using Bite Force Evaluation For Management Of Anterior Mandibular Fractures. Journal of Scientific Dentistry, 6(2), 2016.

18. Sadhwani BS, Anchlia S .Conventional 2.0 $\mathrm{mm}$ miniplates versus $3-\mathrm{D}$ plates in mandibular fractures. Ann Maxillofac Surg. 2013 Jul-Dec; 3(2): 154-159.

19. Agrawal M, Shadab $M$ and Singh RK .Prospective randomized clinical trial comparing bite force in 2-mm locking plates versus 2-mm standard plates in treatment of mandibular fractures. J Oral Maxillofac Surg .2011; 69:1995-2000

20. Wilson IF, Lokeh A, Benjamin CI, Hilger PA, Hamlar DD, Ondrey FG, et al. Prospective comparison of panoramic tomography (zonography) and helical computed tomography in the diagnosis and operative management of mandibular fractures. Plast Reconstr Surg 2001;107(6):1369e75.

21. Turkyilmaz I, Ozan O, Yilmaz B, Ersoy AE. Determination of bone quality of 372 implant recipient sites using Hounsfield unit from computerized tomography: a clinical study. Clin Implant Dent Relat Res 2008; 10(4):238e44.

22. Hashemi HM, Javidi B. Comparison between interpositional bone grafting and osteogenic alveolar distraction in alveolar bone reconstruction. J Oral Maxillofac Surg 2010; 68(8):1853e8.

23. Arimoto $S$, Hasegawa T, Kaneko K, Tateishi C, Furudoi S, Shibuya Y, et al. Observation of osseous healing after intraoral vertical ramus osteotomy: focus on computed tomography values. J Oral Maxillofac Surg 2013; 71(9):1602.

24. Al-Moraissi EA, Mounair RM, El-Sharkawy TM, El-Ghareeb TI. Comparison between three dimensional and standard miniplates in the management of mandibular angle fractures: a prospective, randomized, double-blind, controlled clinical study. Int. J. Oral Maxillofac. Surg. 2015; 44: 316-321.

25. Vineeth $K$, Lalitha RM, Prasad K, Ranganath K, Shwetha V, Singh J. A comparative eval- uation between single noncompression tita-nium miniplate and three dimensional titanium miniplate in treatment of mandibu- lar angle fracture" - a randomized prospec-tive study. J Craniomaxillofac Surg 2013;41: 103-9.

26. Moore E, Bayrak S, Moody M, Key M, Vural E. Hardware removal rates for mandibular angle fractures: comparing the 8-hole strut and Champy plates. J Craniofac Surg 2013; 24:163-5.

27. Marshall W, Mohyuddin N, Burchhardt D, Olson KL, Eicher SA, Brissett AE. Repairing angle of the mandible fractures with a strut plate. JAMA Otolaryngol Head Neck Surg 2013; 139:592-7.

28. Xue AS, Koshy JC, Wolfswinkel EM, Weathers WM, Marsack KP, Hollier Jr LH. A prospective study of strut versus miniplate for fractures of mandibular angle. Craniomaxillofac Trauma Reconstr 2013; 6: 191-6.

29. Hofer SH, Ha L, Ballon A, Sader R, Landes C. Treatment of mandibular angle fractures-linea oblique plate versus grid plate. J Craniomaxillofac Surg 2012; 40:807-11.

30. Singh V, Puri P, Arya S, Malik S, Bhagol A. Conventional versus 3-dimensional mini- 
plate in management of mandibular fracture: a prospective randomized study. Otolaryngol Head Neck Surg 2012; 147:450-5.

31. de Oliveira KP, de Moraes PH, da Silva JSP, de Queiroz WF, Germano AR. In vitro mechanical assessment of $2.0-\mathrm{mm}$ system three-dimensional miniplates in anterior mandibular fractures. Int. J. Oral Maxillofac. Surg. 2014; 43: 564-571.
32. Al-Moraissi EA, El-Sharkawy TM, ElGhareeb TI, Chrcanovic BR. Threedimensional versus standard miniplate fixation in the management of mandibular angle fractures: a systematic review and meta-analysis. Int. J. Oral Maxillofac. Surg. 2014; 43: 708-716.

How to cite this Article: Akshay Kumar ${ }^{1}$,Dhrittiman Pathak ${ }^{2}$, Amit Kumar Verma ${ }^{3}$, Pramod Yadav $^{4}$; Simultaneous Use of 3 D Locking Square Plate and 2 Mm Straight Miniplate for Mandibular Fracture: A Case Report and Review of Literature

Int. Res. Med. Health Sci., 2020; (3-1): 17-24

Source of Support: Nil, Conflict of Interest: None declared.

Received: 27-1-2020; Revision: 18-2-2020; Accepted: 26-02-2020 